\title{
EDUCAÇÃO AMBIENTAL E GASES DO EFEITOS ESTUFA (GEE): UMA ABORDAGEM DO PAPEL DO METANO PARA EDUCAÇÃO BÁSICA
}

\author{
Marc François Richter ${ }^{1}$ \\ Daniela Mueller de Lara ${ }^{2}$ \\ Ricardo de Carly Luz Andreazza ${ }^{3}$
}

Resumo: $O$ efeito estufa natural é um dos fatores mais importantes para manter a Terra quente, pois impede que parte do calor do planeta escape para o espaço. Contudo, o excesso de gases causa o aquecimento global e a Educação Ambiental pode reverter este cenário através da sensibilização, possibilitando a transformação de comportamento e redução dos impactos ambientais. Este trabalho, a partir de revisão bibliográfica, visa contribuir com a articulação e inserção da temática no ensino de ciências, sobretudo nos níveis médio e fundamental. Para isso, é feita uma abordagem da perspectiva da química ambiental discutindo conceitos acerca do metano, sua química, suas fontes e função como gás de efeito estufa, assim como, o efeito sobre a saúde humana.

Palavras-chave: Efeito Estufa; Ação antrópica; Fontes de Metano; Educação Ambiental.

Abstract: The natural greenhouse effect is one of the most important factors to keep the Earth warm, as it prevents some of the heat from the planet escaping into space. However, excess gases cause global warming and Environmental Education can reverse this scenario by raising awareness, enabling behavior transformation and reducing environmental impacts. This work, based on bibliographic review, aims to contribute to the articulation and insertion of the theme in science teaching, especially at the secondary and fundamental levels. For this, an approach is made from the perspective of environmental chemistry discussing concepts about methane, its chemistry, its sources and function as a greenhouse gas, as well as the effect on human health.

Keywords: Greenhouse Effect; Anthropic Action; Methane Sources; Environmental Education.

\footnotetext{
1Universidade Estadual do Rio Grande do Sul. E-mail: marc-richter@uergs.edu.br, Link para o Lattes: http://lattes.cnpq.br/8913363024464502

2 Universidade Estadual do Rio Grande do Sul. E-mail: daniela-lara@uergs.edu.br.

Link para o Lattes: http://lattes.cnpq.br/1557177056454917

${ }^{3}$ Universidade Estadual do Rio Grande do Sul. E-mail: ricardo-andreazza@uergs.edu.br,

Link para o Lattes: http://lattes.cnpq.br/8308294940215128
} 


\section{Introdução}

O efeito estufa natural é um dos fatores mais importantes para manter a Terra quente, pois impede que parte do calor do planeta escape para o espaço. A temperatura média global da Terra seria substancialmente menor sem o efeito estufa, e a vida na Terra, como a conhecemos, seria impossível. Porém, verificase um aumento do aquecimento global e as causas desse fenômeno são múltiplas, tanto de origem natural como de ações antropogênicas (AVELINO; DOMINGUES, 2020).

Os gases que aumentam o efeito estufa incluem metano, dióxido de carbono, óxido nitroso e gases fluorados, entre outros. O aquecimento constante da atmosfera e da superfície da Terra causado pelos gases de efeito estufa tem resultado no aquecimento global desde o início do século anterior. A poluição veicular e industrial, assim como a agropecuária são os principais contribuintes para os gases de efeito estufa e o aquecimento global, sendo o gás metano um dos mais nocivos.

Segundo Liotti e Campos (2021), a crise ambiental instaurada é um problema socioambiental complexo e intensifica a necessidade da organização de caminhos alternativos para o enfrentamento desse fato. Diante disso, a educação é considerada como um dos processos do desenvolvimento humano que proporciona a aquisição do conhecimento, a mudança de comportamento, bem como a formação de novas identidades sociais e, sem dúvida, a Educação Ambiental é um dos meios para avançar na sensibilização e reverter o cenário atual.

Segundo Lopes e Abílio (2021), a Educação Ambiental auxilia e combate a crise ambiental, contribuindo para emancipação e transformação de ações e concepções dos indivíduos diante de si e do mundo. A literatura evidencia a importância de Educação Ambiental nas diferentes fases de ensino, sendo considerada uma importante ferramenta de transformação social e reversão do cenário ambiental que vivemos atualmente (SCHWANTZ et al., 2019; BONATO et al., 2021; LIOTTI; CAMPOS, 2021; PROCÓPIO et al., 2021; RIBEIRO; MALVESTIO, 2021) Ademais, Lins e Fernandes (2021) destacam que a Educação Ambiental é uma condição fundamental para a formação do cidadão e, portanto, é essencial incluir nos planejamentos de aula, em todos os níveis de ensino, conteúdos que abordem problemas e soluções socioambientais.

Conforme Liotti e Campos (2021), verifica-se a falta de uma abordagem interdisciplinar e contextualizada sobre a temática das mudanças climáticas, incluindo os gases de efeito estufa, demonstrando a complexidade dos fatores químicos, geofísicos e atmosféricos que envolvem esse fenômeno. Diante do exposto, este estudo visa contribuir com a articulação e inserção do tema em sala de aula, sobretudo nos níveis médio e fundamental. Para isso, é feita uma abordagem da perspectiva da química ambiental, a partir de revisão bibliográfica, discutindo conceitos acerca do metano, sua química, suas fontes e função como gás de efeito estufa, assim como, o efeito sobre a saúde humana. 


\section{Efeito Estufa: aspectos históricos e natural}

No contexto histórico, Svante Arrhenius (1859-1927), importante cientista sueco, foi o primeiro a afirmar, em 1896, que a combustão de combustíveis fósseis poderia eventualmente resultar em um aumento do aquecimento global. Ele propôs uma relação entre as concentrações atmosféricas de dióxido de carbono $\left(\mathrm{CO}_{2}\right)$ e a temperatura, a base de ideias do matemático e físico francês Jean-Baptiste Fourier (1768-1830) (LACERDA; NOBRE, 2010). Svante Arrhenius e Thomas Chrowder Chamberlin, um geólogo estadunidense, calcularam que as atividades humanas poderiam aquecer a terra ao adicionar $\mathrm{CO}_{2}$ à atmosfera. Isto só foi realmente verificado em 1987; em 1988 foi finalmente reconhecido que o clima era mais quente do que qualquer outro período desde que se iniciarem medidas a partir de 1880. A teoria do efeito estufa foi nomeada e o Painel Intergovernamental sobre Mudanças Climáticas (IPCC) foi fundado pelo Programa Ambiental das Nações Unidas e pela Organização Meteorológica Mundial (CASTRO et al., 2010; ARTAXO, 2014).

Em relação aos aspectos naturais, o efeito estufa é o aumento da temperatura que a Terra experimenta porque certos gases na atmosfera (vapor de água, dióxido de carbono - $\mathrm{CO}_{2}$, óxido nitroso $-\mathrm{N}_{2} \mathrm{O}$, metano $-\mathrm{CH}_{4}$, ozônio $\mathrm{O}_{3}$, entre outros) aprisionam a energia que vem do sol. Estes gases são normalmente chamados de gases de efeito estufa, uma vez que se comportam muito como as placas de vidro em uma estufa. Os painéis de vidro da estufa deixam entrar a luz, mas impedem a fuga de calor e isto é semelhante ao efeito que estes gases têm sobre a terra (ARESTA; DIBENEDETTO, 2021).

A luz solar entra na atmosfera da Terra, passando através dos gases de efeito estufa. Ao chegar à superfície do planeta, a superfície (solo e água) mas também a biosfera absorve a energia da luz solar. Uma vez absorvida, esta energia é enviada de volta para a atmosfera. Parte da energia passa de volta ao espaço, mas grande parte dela permanece presa na atmosfera devido à gases de efeito estufa. Este é o processo completamente natural e, sem estes gases, todo o calor escaparia de volta no espaço e a temperatura média da Terra seria cerca de 30 graus Celsius menor, diminuindo, em muito, a vida no nosso planeta. Desta forma, o efeito estufa é um processo muito importante, pois sem o efeito estufa, a Terra não seria quente o suficiente para que a vida de muitos seres vivos teria se desenvolvida. Com o efeito estufa se tornando mais potente, devido a ações antrópicas, pode tornar a Terra mais quente, do que o habitual, gerando muitos problemas ambientais, para os humanos, plantas e animais (ARESTA; DIBENEDETTO, 2021).

\section{Efeito Estufa: aspectos históricos e natural}

Certas atividades humanas também produzem gases de efeito estufa, tais como: $\mathrm{CO}_{2}, \mathrm{~N}_{2} \mathrm{O}, \mathrm{CH}_{4}$, além de clorofluorcarbonos e hidrofluorcarbonos, que se juntam aos gases de estufa naturais, aumentando, desta forma, na atmosfera. 
A mudança no equilíbrio dos gases de efeito estufa tem efeitos significativos em todo o planeta.

A queima de combustíveis fósseis - carvão, petróleo e gás natural liberam dióxido de carbono para a atmosfera. O uso de combustível fóssil é a principal fonte de $\mathrm{CO}_{2}$. Este gás também pode ser emitido por impactos diretos induzidos pelo homem sobre a silvicultura e outros usos da terra, como por exemplo, através de desmatamento e queima, limpeza de terras para agricultura e degradação de solos (HEGERL, 2007). Da mesma forma, a terra também pode remover $\mathrm{CO}_{2}$ da atmosfera através de reflorestamento, melhoria dos solos e outras atividades. A principal atividade humana que emite $\mathrm{CO}_{2}$ é a combustão de combustíveis fósseis (carvão, gás natural e petróleo) para energia e transporte, embora certos processos industriais e mudanças no uso do solo também emitam este gás. $\mathrm{O} \mathrm{CO}_{2}$ está sendo constantemente trocado entre a atmosfera, o oceano e a superfície terrestre, pois é produzido e absorvido por muitos microrganismos, plantas e animais. Entretanto, as emissões e a remoção de $\mathrm{CO}_{2}$ por esses processos naturais tendem a se equilibrar, na ausência de impactos antropogênicos. Mas, desde que a Revolução Industrial começou por volta de 1800 , as atividades humanas contribuíram substancialmente para a mudança climática ao adicionar $\mathrm{CO}_{2}$ e outros gases que retêm o calor para a atmosfera (EPA, 2021).

Um grupo de gases de efeito estufa chamado clorofluorcarbonos têm sido usado em aerossóis, como latas de spray para cabelos, geladeiras e na fabricação de espuma plástica. Conforme Schwaab et al. (2005), processos industriais, refrigeração e o uso de uma variedade de produtos de consumo contribuem para as emissões de gases $F$, que incluem hidrofluorcarbonos (HFCs), perfluorcarbonos (PFCs), halons e hexafluoreto de enxofre $\left(\mathrm{SF}_{6}\right)$. Os hidrofluorcarbonos são utilizados como refrigerantes, propulsores de aerossóis, agentes de expansão de espuma, solventes e retardadores de fogo.

A principal fonte de emissões destes compostos é sua utilização como refrigerantes - por exemplo, em sistemas de ar-condicionado, tanto em veículos quanto em edifícios. Estes produtos químicos foram desenvolvidos em substituição aos clorofluorcarbonos (CFC) e hidroclorofluorcarbonos (HCFC) porque não empobrecem a camada de ozônio estratosférico. Os clorofluorocarbonos e HCFCs estão sendo eliminados gradualmente sob um acordo internacional, chamado de Protocolo de Montreal. Os HFCs são gases de efeito estufa potentes com alto potencial de aquecimento global, e são liberados na atmosfera durante os processos de fabricação e através de vazamentos, manutenção e descarte do equipamento em que são utilizados (PUROHIT; HÖGLUND-ISAKSSON, 2017).

As atividades agrícolas, como o uso de fertilizantes, são a principal fonte de emissões de $\mathrm{N}_{2} \mathrm{O}$. A combustão de combustível fóssil também gera $\mathrm{N}_{2} \mathrm{O}$, envolvendo os setores econômicos do transporte. O óxido nitroso é emitido quando os combustíveis são queimados. A quantidade de $\mathrm{N}_{2} \mathrm{O}$ emitida pela queima de combustíveis depende do tipo de combustível e da tecnologia de 
combustão, manutenção e práticas operacionais. Atividades humanas adicionais como, gerenciamento de águas residuais e processos industriais estão aumentando a quantidade de $\mathrm{N}_{2} \mathrm{O}$ na atmosfera. O óxido nitroso também está naturalmente presente na atmosfera como parte do ciclo do nitrogênio da Terra, e tem uma variedade de fontes naturais (EPA, 2020). Globalmente, cerca de $40 \%$ do total de emissões de $\mathrm{N}_{2} \mathrm{O}$ vêm de atividades humanas. As moléculas de óxido nitroso permanecem na atmosfera por uma média de 114 anos antes de serem removidas por uma via ou destruídas através de reações químicas. $O$ impacto de 1 quilo de $\mathrm{N}_{2} \mathrm{O}$ no aquecimento da atmosfera é quase 300 vezes maior que o de 1 quilo de dióxido de carbono (SEEG, 2018).

Finalmente, o metano resultante de atividades agrícolas, especialmente via pecuária, gestão de resíduos, de forma anaeróbica, quando os resíduos orgânicos se decompõem, mas também uso de energia e queima de biomassa contribuem para as emissões de $\mathrm{CH}_{4}$ (EPA, 2021). Segundo Lima, Berstein e Valle (2014), o composto também é produzido em lixões, aterros controlados e aterros sanitários sem sistema de queima do $\mathrm{CH}_{4}$ instalado (sistema flare). Cerca de 102 bilhões de metros cúbicos (bcm) de gás natural escaparam das operações globais de petróleo e gás para a atmosfera em 2012. Este gás desperdiçado se traduz em cerca de US $\$ 30$ bilhões de receita perdida a preços médios entregues em 2012, e representa cerca de $3 \%$ da produção global de gás natural (UNECE, 2020).

Posto isto, a seguir são apresentadas as emissões globais de GEE por setor econômico:

$>$ Produção de eletricidade e calor $(25 \%$ das emissões globais de gases de efeito estufa em 2010): A queima de carvão, gás natural e petróleo para eletricidade e calor é a maior fonte única de emissões globais de gases de efeito estufa (SEEG, 2018).

$>$ Indústria (21\% das emissões globais de gases de efeito estufa em 2010): as emissões de GEE da indústria envolvem principalmente combustíveis fósseis queimados no local, em instalações para energia. Este setor também inclui emissões de processos químicos, metalúrgicos e de transformação mineral não associados ao consumo de energia e emissões de atividades de gerenciamento de resíduos (IPCC, 2014).

> Agricultura, silvicultura e outros usos da terra (24\% das emissões globais de gases de efeito estufa em 2010): as emissões de GEE deste setor vêm principalmente da agricultura (cultivo de culturas e pecuária) e do desmatamento. Esta estimativa não inclui o CO2 que os ecossistemas removem da atmosfera ao sequestrar carbono na biomassa, matéria orgânica morta e solos, o que compensa aproximadamente $20 \%$ das emissões deste setor (FAO, 2014; MCGREGOR et al., 2021).

> Transporte (14\% das emissões globais de gases de efeito estufa em 2010): as emissões de gases de efeito estufa deste setor envolvem principalmente combustíveis fósseis queimados para o transporte rodoviário, ferroviário, aéreo 
e marítimo. Quase toda (95\%) da energia do transporte mundial vem de combustíveis à base de petróleo, em grande parte gasolina e diesel (BARTHOLOMEU; PÉRA; CAIXETA FILHO, 2016).

> Edifícios (6\% das emissões globais de gases de efeito estufa em 2010): as emissões de gases de efeito estufa deste setor surgem da geração de energia no local e da queima de combustíveis para aquecimento em edifícios ou para cozinhar em residências. Já as emissões do uso de eletricidade em edifícios estão excluídas e, em vez disso, são contabilizados junto ao setor de Eletricidade e Produção de Calor (BERILL; GILLINGHAM; HERTWICH, 2021).

> Outras fontes de energia ( $10 \%$ das emissões globais de gases de efeito estufa em 2010): esta fonte de emissão de gases de efeito estufa refere-se a todas as emissões do setor de Energia que não estão diretamente associadas à produção de eletricidade ou calor, tais como extração, refino, processamento e transporte de combustível.

\section{Metano: sua química}

O metano $\left(\mathrm{CH}_{4}\right)$ é um gás incolor, inodoro e altamente inflamável composto de um átomo de carbono e quatro átomos de hidrogênio. É composto por um átomo de carbono (C), átomo central, ao qual são ligados 4 (quatro) átomos de hidrogênio através de ligações covalentes. Pode ser produzido natural e sinteticamente, e quando queimado na presença de oxigênio, produz dióxido de carbono e vapor de água.

O metano é o componente principal do gás natural e é utilizado para produzir calor e eletricidade em todo o mundo. O metano também é usado em reações químicas para produzir outros gases importantes como hidrogênio $\left(\mathrm{H}_{2}\right)$ e monóxido de carbono (CO) e negro de fumo, um composto químico que é encontrado em alguns tipos de borracha usada em pneus de automóveis.

\section{Metano como gás do efeito estufa}

O metano é o segundo mais abundante GEE antropogênico depois do $\mathrm{CO}_{2}$, respondendo por cerca de $20 \%$ das emissões globais. O metano é mais de 28-34 vezes mais potente do que o $\mathrm{CO}_{2}$ na captura de calor na atmosfera, a base do período dos últimos 100 anos. Quando medido durante o período dos últimos 20 anos, essa proporção cresce para 84-86 vezes (UNECE, 2020). Nos últimos dois séculos, as concentrações de metano na atmosfera mais do que duplicaram, em grande parte devido a atividades relacionadas ao homem. Como o metano é um gás de efeito estufa poderoso e de curta duração em comparação com o $\mathrm{CO}_{2}$, conseguir reduções significativas teria um efeito rápido e significativo no potencial de aquecimento atmosférico (IPCC, 2007).

A permanência do metano na atmosfera é muito menor que o dióxido de carbono, mas $0 \mathrm{CH}_{4}$ é mais eficiente na captura de radiação do que $\circ \mathrm{CO}_{2}$. $\mathrm{O}$ impacto do $\mathrm{CH}_{4}$ é 25 vezes maior do que o efeito do $\mathrm{CO}_{2}$ analisado no período dos últimos 100 anos (IPCC, 2007).

Revbea, São Paulo, V.16, № 5: 431-445, 2021. 
Globalmente, $50 \%$ a $65 \%$ do total de emissões de $\mathrm{CH}_{4}$ vêm de atividades humanas. O metano é emitido por atividades de energia, indústria, agricultura, uso da terra e gestão de resíduos (IPCC, 2013). Entretanto, ao contrário do $\mathrm{CO}_{2}$, que permanece na atmosfera por séculos, o metano se decompõe rapidamente e a maioria desaparece após uma década, o que significa que a ação pode reduzir rapidamente a taxa de aquecimento global no curto prazo.

Segue abaixo as 4 fontes mais importantes da geração antrópica de $\mathrm{CH}_{4}$ :

- Agricultura (42\%): A pecuária doméstica como gado bovino, suíno, ovino e caprino produz $\mathrm{CH}_{4}$ como parte de seu processo digestivo normal. Além disso, quando o dejeto animal é armazenado ou manejado em lagoas ou tanques de retenção, o $\mathrm{CH}_{4}$ é produzido. Como os humanos criam esses animais para alimentação e outros produtos, as emissões são consideradas relacionadas ao ser humano (RESENDE et al., 2020). Quando as emissões de animais e de esterco são combinadas, o setor agrícola é a maior fonte de emissões de $\mathrm{CH}_{4}$ nos Estados Unidos e no Brasil. Embora menos significativas, as emissões de $\mathrm{CH}_{4}$ também ocorrem como resultado do uso da terra e das atividades de manejo da terra no setor de uso da terra e silvicultura, tais como: incêndios florestais e de pastagens, decomposição de matéria orgânica em zonas úmidas costeiras, etc. (EPA, 2021).

- Energia e Indústria (36\%): Os sistemas de gás natural e petróleo são a segunda maior fonte de emissões de $\mathrm{CH}_{4}$ nos Estados Unidos. O metano é o principal componente do gás natural. O metano é emitido para a atmosfera durante a produção, processamento, armazenamento, transmissão e distribuição de gás natural e a produção, refinamento, transporte e armazenamento de petróleo bruto. A mineração de carvão também é uma fonte de emissões de $\mathrm{CH}_{4}$. Ele é encontrado em depósitos subterrâneos de combustíveis fósseis que têm sido submetidos a altas pressões e temperaturas durante milhões e milhões de anos. Como estes combustíveis são colhidos, extraídos e liberados, $\mathrm{o} \mathrm{CH}_{4}$ também é liberado. Trata-se de um composto difícil de transportar pois vaza facilmente durante a extração de petróleo, carvão e gás natural (EPA, 2021).

- Resíduos de residências e empresas (18\%): O metano é gerado em aterros sanitários à medida que os resíduos se decompõem e no tratamento das águas residuárias. Os aterros sanitários são a terceira maior fonte de emissões de $\mathrm{CH}_{4}$ nos Estados Unidos e podem ser usados para produção de biogás e geração e energia (Costa et al., 2016). O metano também é gerado a partir do tratamento de águas residuárias domésticas e industriais e da compostagem e digestão anaeróbica (EPA, 2021).

Em nível mundial, estima-se que a China, Estados Unidos, Rússia, Índia, Brasil, Indonésia, Nigéria e México sejam responsáveis por quase metade de todas as emissões antropogênicas de metano. As principais fontes de emissão de metano para estes países variam muito. Por exemplo, uma fonte chave de emissões de metano na China é a produção de carvão, enquanto a Rússia emite a maior parte de seu metano a partir de sistemas de gás natural e petróleo (JANARDANAN et al., 2020).

revista brasileira educação ambiental 
Um relatório da ONU reforça que é vital uma redução drástica das emissões de gás metano para enfrentar a mudança climática a curto prazo. Segundo a ONU Notícias (2021), o estudo é o trabalho da Coalizão Clima e Ar Limpo (CCAC), uma parceria global de governos e parceiros não-estatais, e do Programa das Nações Unidas para o Meio Ambiente (UNEP). O relatório ressalta por que a ação internacional é urgentemente necessária, pois as emissões de metano causadas pelo homem estão aumentando mais rapidamente do que em qualquer outro momento desde o início da manutenção de registros nos anos 80 . Mesmo com a pandemia COVID-19 causando uma desaceleração econômica em 2020, que impediu outro ano recorde de emissões de $\mathrm{CO}_{2}$, os dados da Administração Nacional Oceânica e Atmosférica dos Estados Unidos (NOAA, em inglês) mostram que a quantidade de metano na atmosfera atingiu níveis recorde no ano passado (LYON et al., 2021).

Segundo a UNEP (2021), as emissões de metano causadas pela atividade humana podem e devem ser reduzidas em até $45 \%$ nesta década, ajudando assim a manter o aumento da temperatura global dentro de valores razoáveis, em favor do meio ambiente, economia e qualidade de vida, de acordo com o Acordo de Paris sobre mudança climática. Este acordo internacional, assinado por 200 países, visa manter o aumento da temperatura global até 1,5 ○C acima dos níveis pré-industriais até o final deste século. A meta de $1,5{ }^{\circ} \mathrm{C}$ é considerada como a porta de entrada para o aquecimento "perigoso", onde o planeta poderia sofrer sérios efeitos adversos da mudança climática. Para que isso seja alcançado, "medidas urgentes" são necessárias a fim de reduzir o metano se o aquecimento global for mantido dentro de um limite estabelecido no referido acordo (ONU NOTíCIAS, 2021). O corte do metano é a alavanca mais forte que o mundo tem para retardar a mudança climática durante os próximos 25 anos e complementa os esforços necessários para reduzir o dióxido de carbono. Os benefícios para a sociedade, a economia mundial e o meio ambiente são numerosos e superam em muito o custo.

De acordo com a Convenção-Quadro das Nações Unidas sobre Mudança Climática (UNFCCC), a estabilização dos gases de efeito estufa, incluindo $\mathrm{CH}_{4}$, é necessária para combater o problema da mudança climática global (ROMANAK et al., 2021). A emissão de $\mathrm{CH}_{4}$ tem efeitos negativos locais, regionais e globais sobre o meio ambiente, o ser humano e os seres vivos. A função crítica de uma melhor gestão dos resíduos sólidos urbanos é reduzir os problemas associados à poluição local por resíduos, e mudar a emissão de $\mathrm{CH}_{4}$ para emissões de $\mathrm{CO}_{2}$ através de instalações de geração de energia. $\mathrm{Na}$ hierarquia de gerenciamento de resíduos, recomenda-se o lixo, redução, reutilização, reciclagem e recuperação para padrões de consumo e produção sustentáveis em países desenvolvidos e em desenvolvimento. Ari e Sentürk (2020) observaram uma relação invertida entre as emissões de $\mathrm{CH}_{4}$ per capita e o PIB per capita. O estudo recomenda que o aumento do PIB per capita deve ser alinhado com políticas fortes para a transformação dos países em práticas sustentáveis e padrões de consumo e produção. 


\section{Metano, ozônio e a saúde humana}

$\mathrm{O}$ metano $\left(\mathrm{CH}_{4}\right)$ contribui para o crescente contexto global concentração de ozônio troposférico $\left(\mathrm{O}_{3}\right)$, um poluente atmosférico associado à mortalidade prematura. Como o metano, o ozônio também é um importante gás de efeito estufa. A redução das emissões de metano diminui, portanto, o ozônio superficial em todos os lugares, ao mesmo tempo em que retarda o aquecimento da atmosfera, mas embora a mitigação do metano tenha sido considerada para abordar a mudança climática, se falou pouco na importância do metano para a qualidade do ar (VAN DINGENEN et al., 2018).

Segundo Filippidou e Koukouliata (2011) e Rice et al. (2014), a ação global para reduzir as emissões de metano poderia, até o ano de 2050, evitar 70.000 a 130.000 mortes/ano prematuras devido à poluição pelo ozônio no mundo. As doenças relacionadas a essas mortes prematuras são: 1) respiratórias, 2) doenças cardíacas, além de 3) vias respiratórias danificadas e tecido pulmonares.

A Avaliação Global de Metano descreve os benefícios da diminuição do metano, um ingrediente chave na poluição atmosférica, que inclui a prevenção de cerca de 260 mil mortes prematuras e 775 mil visitas hospitalares relacionadas à asma anualmente, assim como 25 milhões de toneladas em perdas de safra (UNEP, 2021). Segundo este estudo, os benefícios são: 1) a rápida redução do aquecimento, que pode ajudar a evitar pontos perigosos de aquecimento do clima; 2) melhoria da qualidade do ar que pode salvar centenas de milhares de vidas; 3) melhoramentos na segurança alimentar, evitando perdas de colheitas; e 4) criação de empregos através de esforços de mitigação enquanto aumenta a produtividade através da redução do estresse térmico.

O ozônio troposférico é produzido pela interação da luz solar com emissões de óxidos de nitrogênio $\left(\mathrm{NO}_{\mathrm{x}}\right)$, monóxido de carbono $(\mathrm{CO})$, compostos orgânicos voláteis (COV) e metano $\left(\mathrm{CH}_{4}\right)$. A comparação das observações de ozônio no final do século 20 com dados anteriores mostra que, no último século, os níveis de ozônio no nível do solo no continente europeu mais do que dobraram. Embora os níveis de pico de ozônio de curto prazo na Europa e na América do Norte tenham diminuído nas últimas décadas como resultado da redução das emissões de $\mathrm{NO}_{x}$ e COV, não é possível encontrar tal tendência para os níveis de longo prazo (ZHANG; WEL; FANG, 2019).

Desde a era pré-industrial, as concentrações de metano mais do que duplicaram. E após um período de estagnação, elas estão aumentando novamente desde a última década. De acordo com Van Dingenen et al. (2018), em todo o mundo, as emissões de metano aumentaram 17\% entre 1990 e 2012, em comparação com um aumento de $53 \%$ nas emissões de CO2. Caso a economia mundial continuar, sem diminuir gases do efeito estufa ("business as usual"), as emissões globais de metano produzidas pelo homem podem aumentar de 35-100 por cento até 2050, a partir do nível de 2010 de cerca de $330 \mathrm{Tg}$. Em contraste, cenários mais sustentáveis, como os que visam as metas 
do $2^{\circ}$ Acordo de Paris, projetaram reduções de emissão de metano de até 50 por cento até 2050.

Assim, a mitigação do metano oferece uma oportunidade única de melhorar a qualidade do ar globalmente e pode ser um componente econômico da gestão internacional do ozônio, trazendo múltiplos benefícios para a qualidade do ar, a saúde pública, agricultura, clima e energia (VAN DINGENEN et al., 2018).

\section{Desafios de aproveitar o metano produzido por ação antrópica}

Ainda não estão muito disseminados esforços para capturar e utilizar o metano produzido por ação antrópica, de forma lucrativa. Embora existem múltiplos benefícios, a recuperação do metano não está difundida pelas seguintes razões:

- O metano é geralmente um subproduto secundário nos processos industriais a partir dos quais é emitido. As minas de carvão, por exemplo, procuram desprender o metano do funcionamento da mina porque ele pode causar explosões. Historicamente, as empresas de mineração não têm visto o metano associado como um recurso energético por si só.

- As entidades responsáveis pelas emissões de metano muitas vezes não estão familiarizadas com tecnologias existentes para a recuperação de metano ou com o potencial para projetos lucrativos de recuperação. Isto é especialmente verdadeiro nos países em desenvolvimento onde um melhor acesso à informação e treinamento técnico seria benéfico para gerar apoio a projetos de recuperação de metano.

- O mau funcionamento dos mercados de energia e a insolvência financeira dos serviços públicos e dos municípios de muitos países não conseguem proporcionar ao setor privado um clima que atraia seus investimentos em projetos de captação e utilização de metano.

Existem opções baratas e até rentáveis para reduzir as emissões de metano em um período de tempo relativamente curto. Em particular, reduções importantes de emissões podem ser obtidas por:

- Redução do consumo de energia, substituição de combustíveis fósseis, modernização da velha produção de gás e petróleo e da infraestrutura de distribuição de gás para reduzir vazamentos não intencionais (UNECE, 2020; SANTOS; FERREIRA FILHO, 2017).

- Fazer a máxima separação e tratamento de resíduos, e usar cada vez menos aterros sanitários para resíduos biodegradáveis. Estima-se que o potencial de redução global no setor de aterros sanitários para resíduos sólidos seja de aproximadamente $61 \%$ das emissões de base até 2030 , dos quais $12 \%$ podem ser atingidos a custos relativamente baixos ou nulos (CARDOSO; CARDOSO, 2016). 
- Já para o caso de países em desenvolvimento como o Brasil, a desativação de lixões, usando cada vez mais aterros sanitários, com instalação de tecnologia que transforma $\mathrm{o}$ metano em $\mathrm{CO}_{2}$ (flare, produção de energia) ou ainda envasamento/engarrafamento do metano produzido (via biogás) em aterro sanitário para fins de uso como GNV (CAICEDO-CONCHA et al., 2019; LIMA; BERSTEIN; VALLE, 2014)

- Melhorar os padrões sanitários nos países em desenvolvimento e implementar padrões ocidentais para o saneamento de águas residuais. O Novo Marco do Saneamento básico, no Brasil, aprovado em julho de 2020 (Lei no 14.026/20), estabelecendo um novo quadro regulamentar para o saneamento básico do país) (BRASIL, 2020). Se quer, assim, alcançar o acesso universal aos serviços de saneamento básico até ao ano 2033, sendo $99 \%$ de todos os lares do Brasil com abastecimento de água e $90 \%$ com eliminação e tratamento de esgotos (SOUSA, 2020).

- Seguindo as recomendações da FAO para melhorar a saúde animal e a eficiência da produção de leite e carne (RESENDE et al., 2020). A fermentação entérica de ruminantes - uma importante fonte de metano - também pode ser reduzida, por exemplo, através do ajuste da dieta dos animais e da vacinação (PREDREIRA et al., 2013; PHAND; PANKAJ, 2021).

- Mudando os hábitos alimentares através da redução do consumo de carne e laticínios, o que também traria benefícios adicionais à saúde (ZACH; BLACKSTONE, 2021).

\section{Considerações finais}

Este trabalho apresenta, de forma descritiva e abrangente, os principais conceitos acerca da química ambiental considerados necessários e essenciais para a compreensão do fenômeno do efeito estufa e do aquecimento global. Com a abordagem de conceitos sobre o metano, sua química, suas fontes e função como gás de efeito estufa, e seu efeito sobre o ozônio ao nível do solo e, portanto, sobre a saúde humana possibilita-se reflexões no contexto da temática ambiental.

O efeito estufa natural é um dos fatores mais importantes para manter a Terra quente, pois impede que parte do calor do planeta escape para o espaço. A temperatura média global da Terra seria substancialmente menor sem o efeito estufa, e a vida na Terra, como a conhecemos, seria impossível. Entre os gases que aumentam o efeito estufa destacam-se metano, dióxido de carbono, óxido nitroso e gases fluorados, entre outros. O gás metano é produzido por uma série de fontes antropogênicas (de origem humana) e naturais, tais como aterros sanitários, emissões fugitivas de sistemas de petróleo e gás natural, agricultura, tratamento de águas residuais, além da combustão estacionária e móvel.

Contudo, o aquecimento constante da atmosfera e da superfície da Terra causado pelos gases de efeito estufa tem resultado no aquecimento global desde 
o início do século anterior. A poluição veicular e industrial, assim como a agropecuária são os principais contribuintes para os gases de efeito estufa e o aquecimento global, sendo o gás metano um dos mais nocivos. Portanto, a Educação Ambiental aliada a ações de sensibilização ambiental pode reverter o atual cenário. Além disso, é extremamente importante a ampliação de ações conscientes tomadas por governos, empresas e sociedade para reduzir as emissões de metano.

A partir da discussão teórica apresentada neste artigo, espera-se contribuir para o debate sobre este importante tema ambiental, fomentado a sua inserção na sala de aula, de maneira multidisciplinar, principalmente do Ensino Médio e Fundamental visando engajar a comunidade escolar na construção de uma compreensão crítica no viés científico, promovendo a sensibilização ambiental.

\section{Referências}

ARESTA, M.; DIBENEDETTO, A. The Atmosphere, the Natural Cycles, and "Greenhouse Effect”. The Carbon Dioxide Revolution. Springer, Cham., 2021.

ARI, I.; ŞENTÜRK, H. The relationship between GDP and methane emissions from solid waste: A panel data analysis for the G7. Sustainable Production and Consumption, v. 23, p. 282-290, 2020.

ARTAXO, P. Mudanças climáticas e o Brasil. Revista USP, n. 103, p. 8-12, 2014.

BARTHOLOMEU, B.D.; PÉRA, T.G.; CAIXETA-FILHO, J.V. Logística sustentável: avaliação de estratégias de redução das emissões de $\mathrm{CO} 2$ no transporte rodoviário de cargas. Journal of Transport Literature, v. 10, n. 3, 2016.

BERRILL, P.; GILLINGHAM, K.T.; HERTWICH, E.G. Drivers of change in US residential energy consumption and greenhouse gas emissions, 1990-2015. Environmental Research Letters, v. 16, n. 3, p. 030445, 2021.

BONATO, S.; SCHWANTZ, P.I.; PRESTES, M.M.B.; BOHRER, R.E.G.; LARA, D.M. administração pública no âmbito da gestão de resíduos sólidos: um diagnóstico no município de Soledade/RS. Revista Metropolitana de Sustentabilidade, v. 11, n. 1, 2021.

BRASIL. Lei no 14.026, de 15 de julho de 2020. Atualiza o marco legal do saneamento básico e dá outras providências. Diário Oficial da União 2020; 16 jul. Disponível em: <https://www.in.gov.br/web/dou/-/lei-n-14.026-de-15-dejulho-de-2020-267035421>. Acesso em: 22 maio 2021.

CAICEDO-CONCHA, D.M. et al. The potential of methane production using aged landfill waste in developing countries: A case of study in Colombia. Cogent Engineering, v. 6, n. 1, p. 1-15, 2019.

CARDOSO, F.C.I.; CARDOSO, J.C. O problema do lixo e algumas perspectivas para redução de impactos. Ciência e Cultura, São Paulo, v. 68, n. 4, p. 25-29, 2016. 
CASTRO, B.M. et al. O mar de amanhã, com as mudanças climáticas de hoje. Ciência e Cultura, São Paulo, v. 62, n. 3, p. 40-42, 2010.

COSTA, A.N.; DOMINGUES, E.G.; MEDEIROS, P.; STACH, A.H.M. Análise de Risco do Aproveitamento Energético do Biogás de Aterros Sanitários para a Geração de Eletricidade. Revista Tecnia, v. 1, n. 2, p. 111-127, 2016.

EPA. Greenhouse gas emissions: nitrous oxide emissions. 2020. Disponível em: <https://www.epa.gov/ghgemissions/overview-greenhouse-gases\#nitrousoxide>. Acesso em: 22 maio 2021.

EPA. Greenhouse gas emissions: methane. 2021. Disponível em: $<$ https://www.epa.gov/ghgemissions/overview-greenhouse-gases\#methane>.

Acesso em: 22 maio 2021.

FAO. Agriculture, Forestry and Other Land Use Emissions by Sources and Removals by Sinks. Climate, Energy and Tenure Division, FAO, 2014. Disponível em: <http://www.fao.org/3/i3671e/i3671e.pdf>. Acesso: 23/05/2021.

FILIPPIDOU, E. C.; KOUKOULIATA, A. Ozone effects respiratory system. Progress in Health Sciences, v. 1, n. 2, 2011.

HEGERL, G. C. et al. Understanding and attributing climate change. In: SOLOMON S. et al., eds. Climate change 2007: the physical science basis. Contribution of the Working Group I to the Fourth Assessment Report of the Intergovernmental Panel on Climate Change. Cambridge, UK and New York: Cambridge University Press. p. 663-746, 2007.

IPCC. Climate Change 2007: The Physical Science Basis. Contribution of Working Group I to the Fourth Assessment Report of the Intergovernmental Panel on Climate Change. S. Solomon, D. Qin, M. Manning, Z. Chen, M. Marquis, K.B. Averyt, M. Tignor and H.L. Miller (eds.). Cambridge University Press. Cambridge, United Kingdom $996 \quad$ pp., 2007. Disponível em: $<$ https://www.ipcc.ch/report/ar4/syr/>. Acesso em: 23 maio 2021.

IPCC. Climate 2013: The Physical Science Basis. Contribution of Working Group I to the Fifth Assessment Report of the Intergovernmental Panel on Climate Change. Stocker, T. F., D. Qin, G.-K. Plattner, M. Tignor, S. K. Allen, J. Boschung, A. Nauels, Y. Xia, V. Bex and P. M. Midgley (eds.). Cambridge University Press, Cambridge, United Kingdom and New York, NY, USA, 1585 pp., 2013. Disponível em: <https://www.ipcc.ch/report/ar5/wg1/>. Acesso em: 23 maio 2021.

IPCC. Climate Change 2014: Mitigation of Climate Change. Contribution of Working Group III to the Fifth Assessment Report of the Intergovernmental Panel on Climate Change [Edenhofer, O., R. et al. (eds.)]. Cambridge University Press, Cambridge, United Kingdom and New York, NY, USA, 2014. Disponível em: $<$ https://www.ipcc.ch/report/ar5/wg3/>. Acesso em 25 maio 2021.

JANARDANAN, R. et al. Country-Scale Analysis of Methane Emissions with a High-Resolution Inverse Model Using GOSAT and Surface Observations. Remote Sensing, v. 12, n. 3, p. 375, 2020. 
LACERDA, F.; NOBRE, P. Aquecimento global: conceituação e repercussões sobre o Brasil. Revista Brasileira de Geografia Física, v. 03, p. 14-17, 2010.

LIMA, A.K.C.; BERSTEIN, A.; VALLE, T.F. Aproveitamento energético do biogás a partir de resíduos sólidos. Revista Educação Pública, v. 16, p. 1-8, 2014.

LIOTTI, L.C.; CAMPOS, M.A.T. Livros didáticos do ensino médio e o conhecimento escolar sobre mudanças climáticas. Revista Brasileira de Educação Ambiental, v. 16, n. 2, p. 19-36, 2021.

LINS, N. da S.; FERNANDES, N. N. B. Análise da práxis pedagógica de Educação Ambiental nas disciplinas Ciências e Geografia, modalidade EJA. Revista Brasileira de Educação Ambiental, v. 16, n. 3, p. 126-141, 2021.

LOPES, T. da S.; ABÍLIO, F. J. P. Educação Ambiental Crítica: (re)pensar a formação inicial de professores/as. Revista Brasileira de Educação Ambiental, v. 16, n. 3, p. 38-58, 2021.

LYON, D. R. et al. Concurrent variation in oil and gas methane emissions and oil price during the COVID-19 pandemic. Atmospheric Chemistry and Physics, v. 21, p. 6605-6626, 2021.

MCGREGOR, A.; RICKARDS, L.; HOUSTON, D.; GOODMAN, M.K.; BOJOVIC, M. The Biopolitics of Cattle Methane Emissions Reduction: Governing Life in a Time of Climate Change. Antipode, fev. 2021.

ONU Notícia. Cut methane emissions to avert global temperature rise, UNbacked study urges. 2021. Disponível em: <https://unece.org/challenge>. Acesso em: 23 maio 2021.

PEDREIRA, M. dos S. et al. Methane emissions and estimates of ruminal fermentation parameters in beef cattle fed different dietary concentrate levels. Revista Brasileira de Zootecnia, v. 42, n. 8, p. 592- 598, 2013.

PHAND, S.; PANKAJ, P.K. Climate-Resilient Livestock Farming to Ensure Food and Nutritional Security. In: Hebsale Mallappa V.K., Shirur M. (eds) Climate Change and Resilient Food Systems. Springer, Singapore, 2021.

PROCÓPIO, J.C.; VALE, K.C.; COSTA, F.J.; BARROS, C.F.A. A interdisciplinaridade da Educação Ambiental nas práticas educacionais de uma escola de ensino fundamental em Contagem (MG). Revista Brasileira de Educação Ambiental, v. 16, n. 3, p. 301-315, 2021.

PUROHIT, P.; HÖGLUND-ISAKSSON, L. Global emissions of fluorinated greenhouse gases 2005-2050 with abatement potentials and costs. Atmospheric Chemistry and Physics, v. 17, p. 2795-2816, 2017.

RESENDE, L. O.; MÜLLER, M. D.; KOHMANN, M. M. et al. Silvopastoral management of beef cattle production for neutralizing the environmental impact of enteric methane emission. Agroforestry Systems, v. 94, p. 893-903, 2020.

RIBEIRO, M.T.; MALVESTIO, A.C. O ensino da temática ambiental nas Instituições de Ensino Superior no Brasil. Revista Brasileira de Educação Ambiental, v. 16, n. 3, p. 347-361, 2021. 
RICE, M.B.; THURSTON, G.D.; BALMES, J.R.; PINKERTON, K.E. Climate change. A global threat to cardiopulmonary health. American Journal of Respiratory and Critical Care Medicine, v. 189, n. 5, p. 512-519, 2014.

ROMANAK, K.; FRIDAHL, M.; DIXON, T. Attitudes on Carbon Capture and Storage (CCS) as a Mitigation Technology within the UNFCCC. Energies, v. 14, n. 3, p. 629, 2021.

SANTOS, J.A.; FERREIRA FILHO, J.B.S. Substituição de combustíveis fósseis por etanol e biodiesel no Brasil e seus impactos econômicos: uma avaliação do plano nacional de energia 2030. Pesquisa e Planejamento Econômico, v. 47, n. 3, p. 185-216, 2020.

SCHWAAB, K. et al. Fluorinated Greenhouse Gases in Products and Processes: An Evaluation of Technical Measures to Reduce Greenhouse Gas Emissions. $2005 . \quad$ Diponível em: $<$ http://citeseerx.ist.psu.edu/viewdoc/download?doi=10.1.1.117.1965\&rep=rep1 \&type=pdf $>$. Acesso em 22 maio 2021.

SCHWANTZ, P.I.; ROTH, J.C.G.; SANTOS, E.F.; LARA, D.M. Reciclagem de resíduos oleosos: ação de sensibilização ambiental com alternativas de reciclagem pela produção artesanal de sabão. Revista Estudo \& Debate, v. 26, n. 1, 2019.

SEEG. Sistema de Estimativas de Emissões e Remoções de Gases de Efeito Estufa. Emissões de GEE no Brasil e suas implicações para políticas públicas e a contribuição brasileira para o Acordo de Paris. Documento de Análise. Observatório do Clima. 51p. 2018.

SOUSA, A. C. A. O que esperar do novo marco do saneamento? Cadernos de Saúde Pública, v. 36, n. 12, dez 2020.

UNECE. Methane management: the challenge. 2020. Disponível em: https://unece.org/challenge. Acesso em: 22 maio 2021.

UNEP. Global Methane Assessment: Benefits and Costs of Mitigating Methane Emissions. 2021. Disponível em: <https://www.unep.org/resources/report/globalmethane-assessment-benefits-and-costs-mitigating-methane-emissions $>$.

Acesso em: 23 maio 2021.

VAN DINGENEN, R.; CRIPPA, M.; JANSSENS-MAENHOUT, G.; GUIZZARDI, D.; DENTENER, F. Global trends of methane emissions and their impacts on ozone concentrations. EUR 29394 EN, Publications Office of the European Union, Luxembourg, 2018.

ZACH, C.; BLACKSTONE, N.T. Identifying the links between consumer food waste, nutrition, and environmental sustainability: a narrative review. Nutrition Reviews, v. 79, n. 3, p. 301-314, 2021.

ZHANG, J.; WEI, Y.; FANG, Z. Ozone Pollution: A Major Health Hazard Worldwide. Frontiers in Immunology, v. 10, p. 2518, 2019. 